\title{
Noursamycins, Chlorinated Cyclohexapeptides Identified from Molecular Networking of Streptomyces noursei NTR-SR4
}

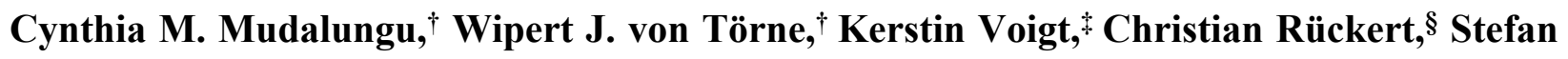
Schmitz, $\|$ Olga N. Sekurova, ${ }^{\perp}$ Sergey B. Zotchev,,$^{\perp *}$ Roderich D. Süssmuth ${ }^{\dagger *}$

$\dagger$ Technische Universität Berlin, Institut für Chemie, Straße des 17. Juni 124, 10623 Berlin, Germany

$¥$ Jena Microbial Resource Collection, Leibniz Institute for Natural Product Research and Infection Biology (HKI), Beutenbergstraße 11a, 07745 Jena, Germany

§Centrum für Biotechnologie (CeBiTec), Universität Bielefeld, Universitätsstraße 25, 33615

Bielefeld, Germany

\|Department of Biotechnology, Norwegian University of Science and Technology, Trondheim, Norway. Current address: Bayer AG, Aprather Weg 18a, 42113 Wuppertal, Germany

${ }^{\perp}$ Department of Pharmacognosy, University of Vienna, Althanstraße 14, 1090 Wien, Austria

\section{Supporting Information}




\section{Table of content}

Figure S1: Total Ion Chromatogram of the MeOH crude extract (M5288 medium) from $S$. noursei NTR-SR4

Figure S2: Mass spectrum of noursamycin A and B

Figure S3: Isotopic pattern indicating chlorine atom incorporation

Figure S4: Tandem $\mathrm{MS}^{2}$ of noursamycin A performed on an ESI-LTQ Orbitrap XL MS system

Figure S5: Proton NMR spectrum of noursamycin A in DMSO- $d_{6}$

Figure S6: COSY NMR spectrum of noursamycin A in DMSO- $d_{6}$

Figure S7: TOCSY NMR spectrum of noursamycin A in DMSO- $d_{6}$

Figure S8: HSQC NMR spectrum of noursamycin A in DMSO- $d_{6}$

Figure S9: NOESY NMR spectrum of noursamycin A in DMSO- $d_{6}$

Figure S10: HMBC NMR spectrum of noursamycin A in DMSO- $d_{6}$

Figure S11: Proton NMR spectrum of noursamycin B in DMSO- $d_{6}$

Figure S12: COSY NMR spectrum of noursamycin B in DMSO- $d_{6}$

Figure S13: TOCSY NMR spectrum of noursamycin B in DMSO- $d_{6}$

Figure S14: HSQC NMR spectrum of noursamycin B in DMSO- $d_{6}$

Figure S15: HMBC NMR spectrum of noursamycin B in DMSO- $d_{6}$

Figure S16: GC-EI-MS chromatogram of norsamycin A

Figure S17: GC-EI-MS chromatogram of norsamycin B

Figure S18: Comparison of the derivatized isoleucine isomers by chiral GC-EI-MS

Figure S19: Partial COSY spectrum of 803 Da peptide indicating 6-amide protons.

Figure S20: The tandem MS/MS fragmentation for noursamycin F performed on an ESI-LTQ Orbitrap XL MS system

Table S1: Deduced NMR data from the structure elucidation of noursamycin A in DMSO- $d_{6}$

Table S2: Predicted gene functions from the putative gene cluster 


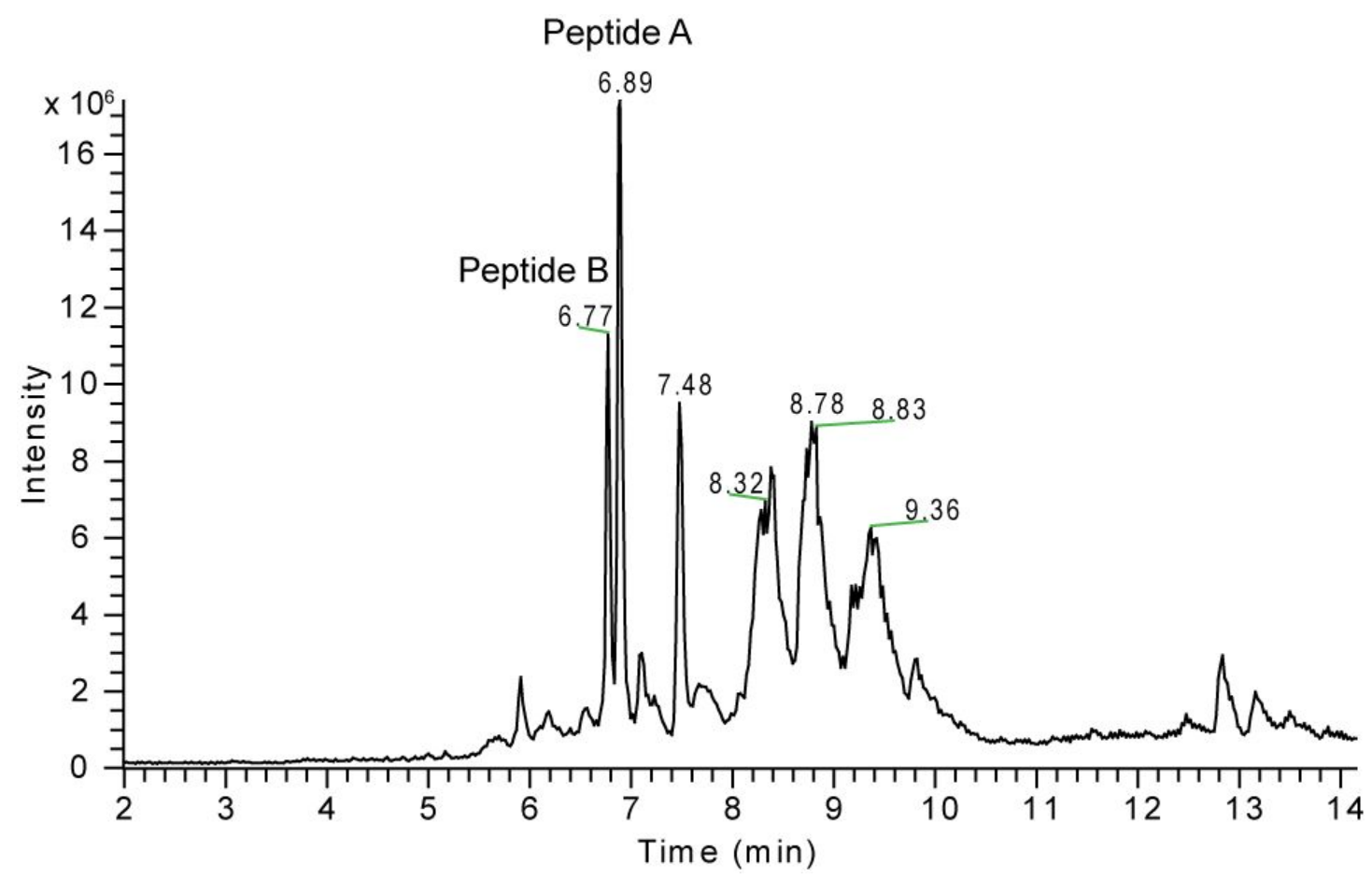

Figure S 1: Total Ion Chromatogram of the MeOH crude extract (M5288 medium) from $S$. noursei NTR-SR4 used for the screening of the chlorinated peptides.

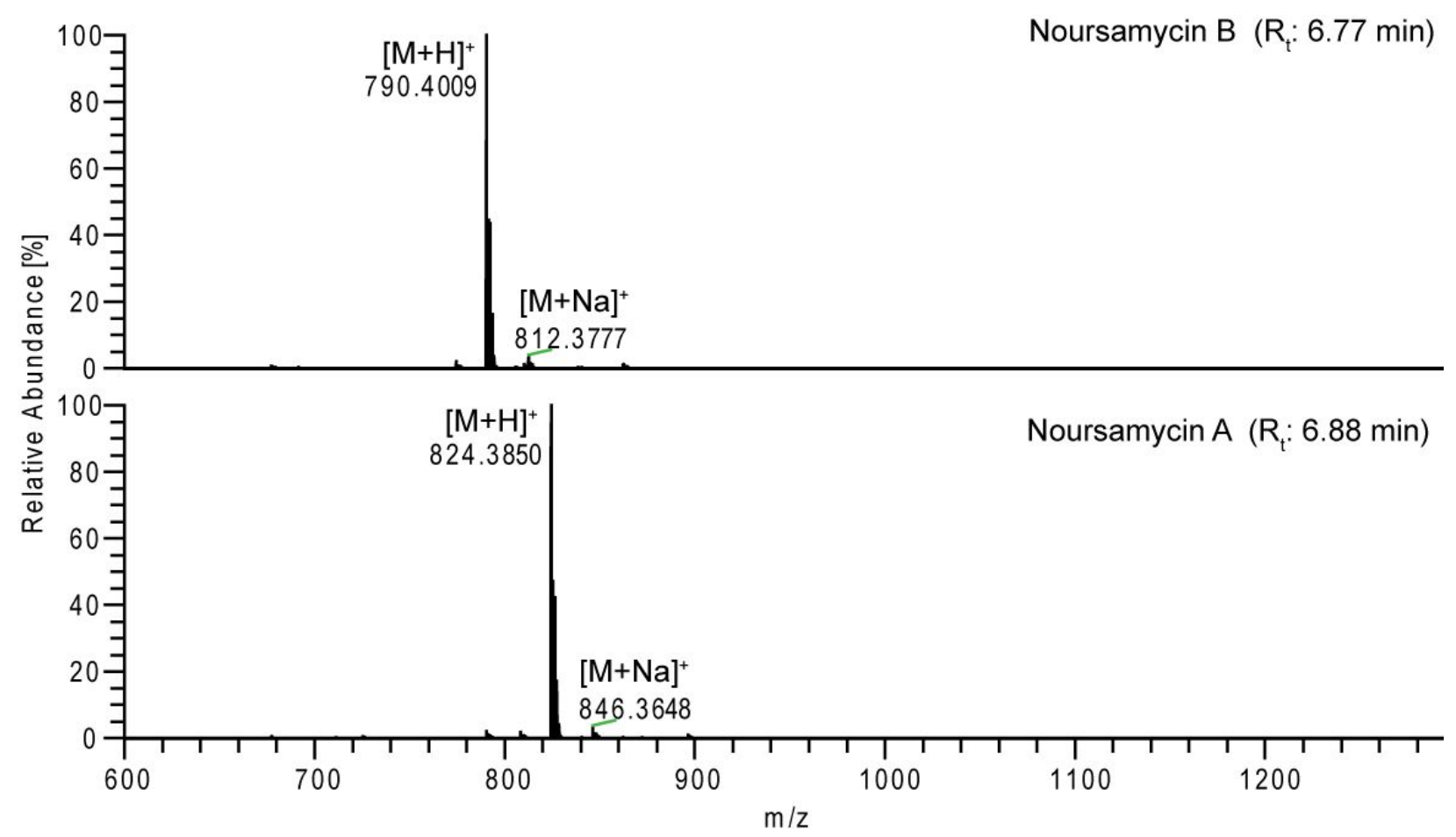

Figure S 2: Mass spectrum of noursamycin A and B 


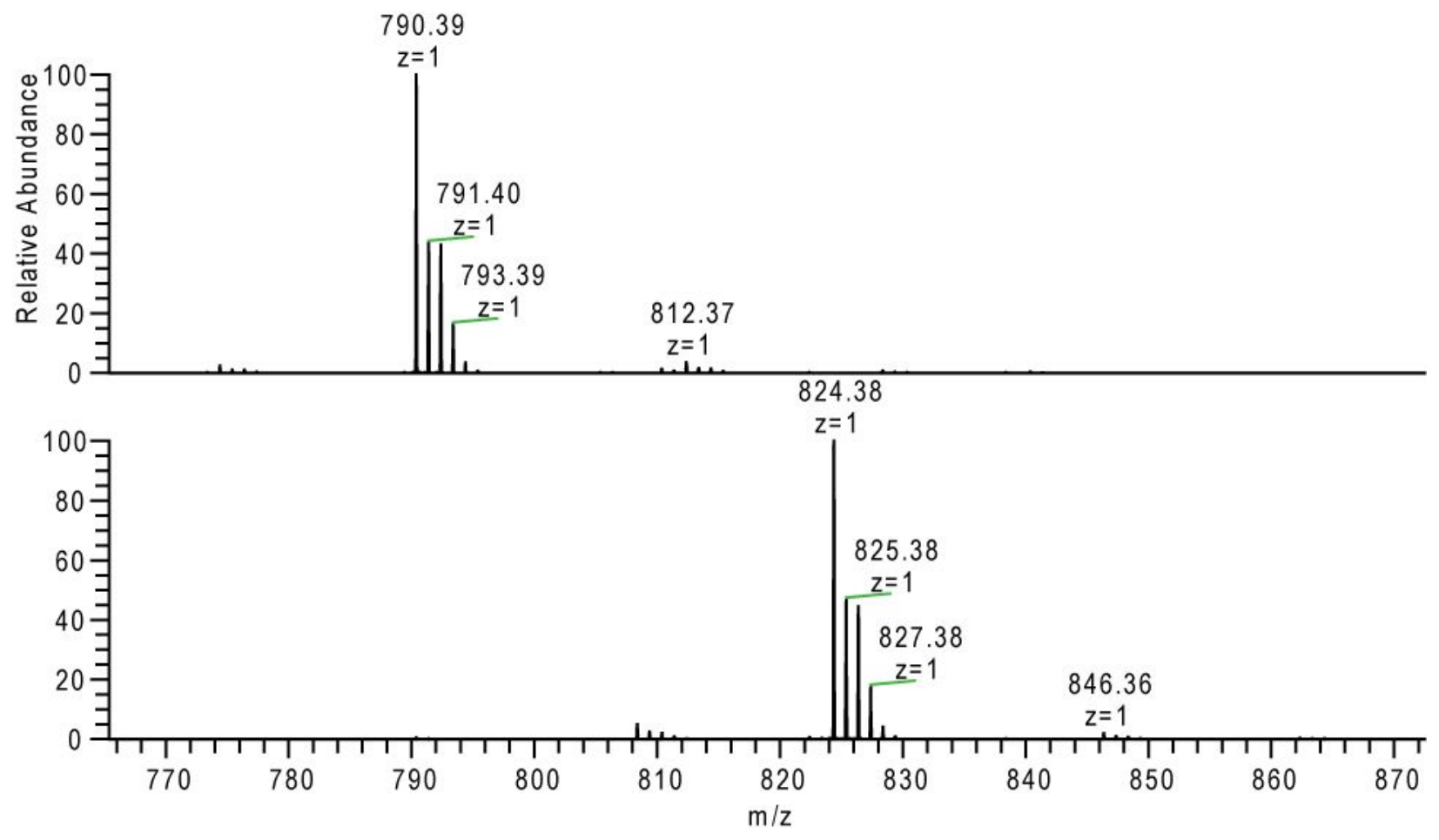

Figure S 3: Isotopic pattern indicating chlorine atom incorporation 


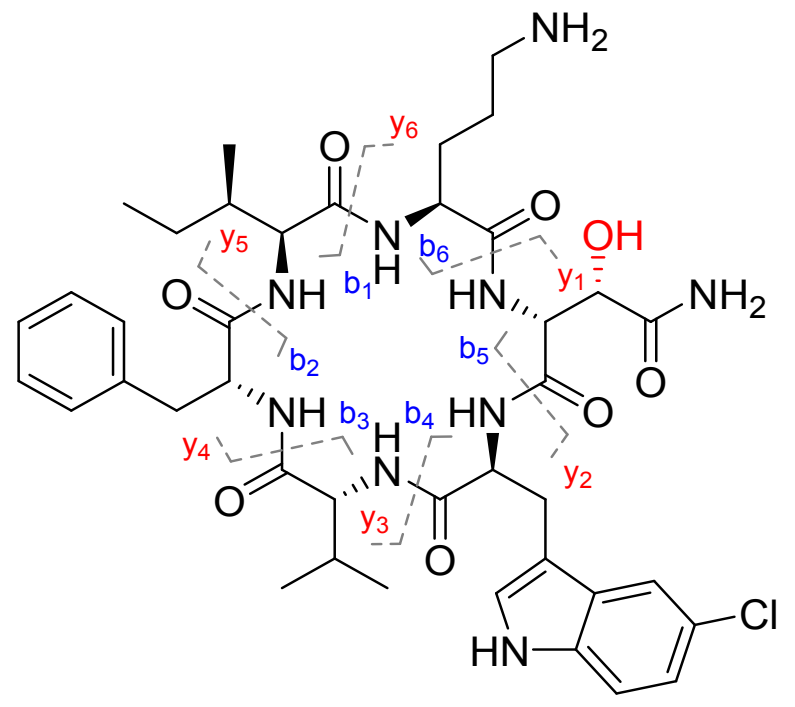

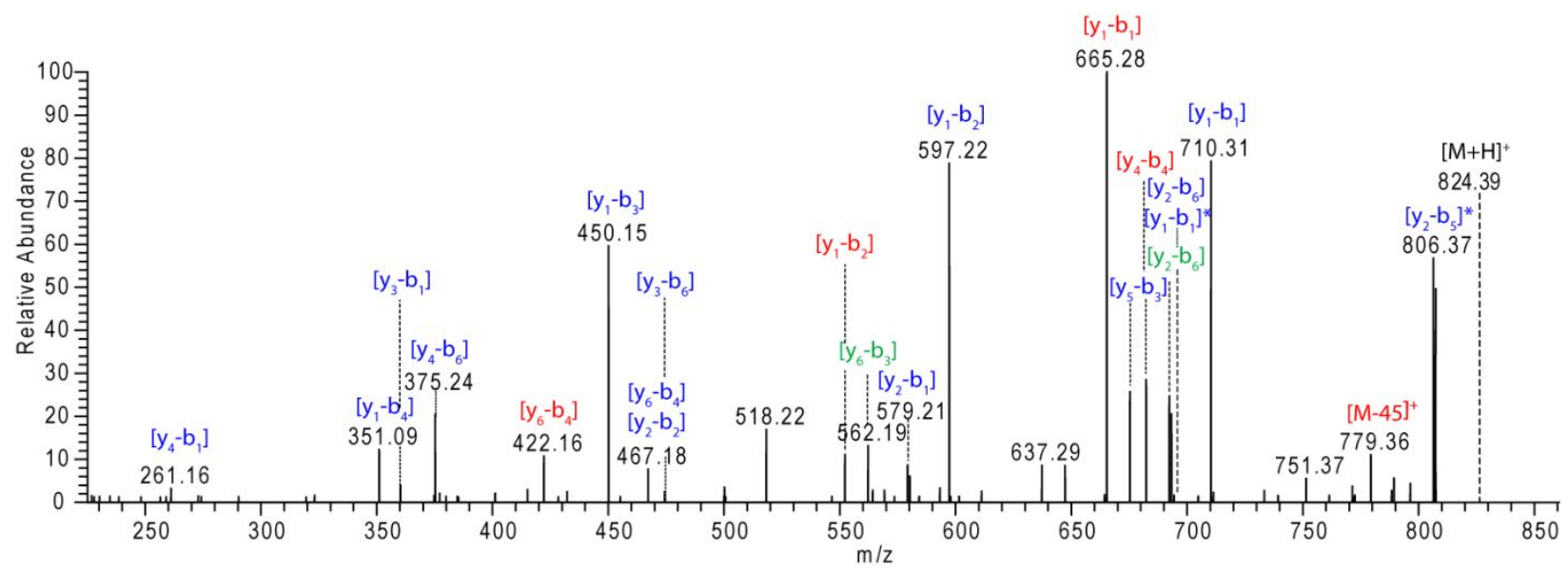

Figure S 4: Tandem $\mathrm{MS}^{2}$ of peptide A performed on an ESI-LTQ Orbitrap XL MS system. The identified ' $b$ '" and ' $y$ '" ions are illustrated as obtained at a collision energy of $30 \mathrm{eV}$. The numerical values do not represent the actual positions of the moieties in the structure. The ion series with asterisk $(*)$ represents fragment obtained after the loss of a water molecule (in such a case corresponding to water loss from the hydroxy group-Asn). The ions annotated in blue are the observed fragments without modifications. Red indicates the ions formed after a neutral loss of $45 \mathrm{Da}$ which is assumed to originate from the hydroxy group-Asn moiety and green represents the ions formed after $45 \mathrm{Da}$ loss followed by rearrangement of atoms at the hydroxy group-Asn. 


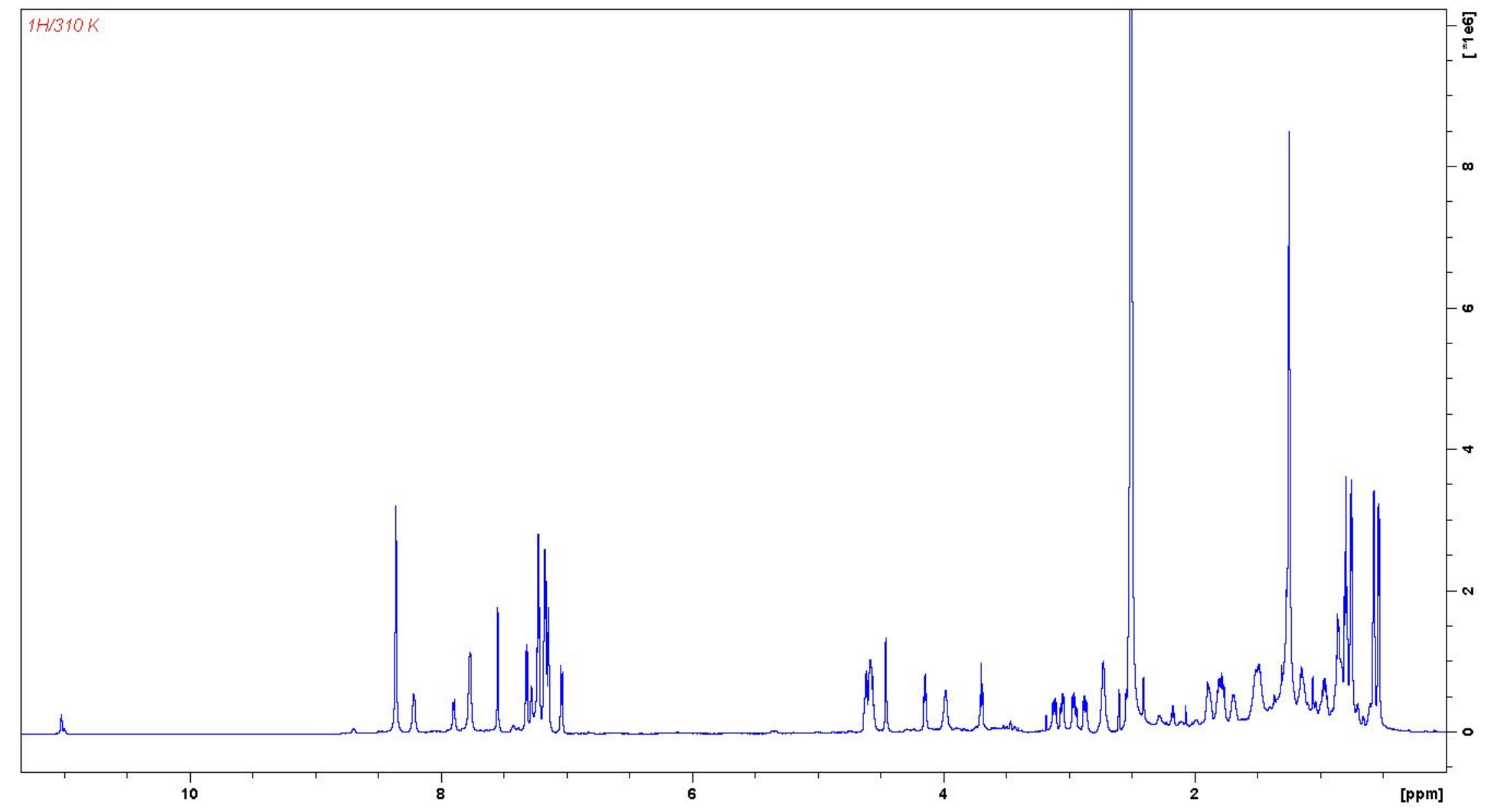

Figure S 5: Proton NMR spectrum of noursamycin A after water suppression (in DMSO- $d_{6}$ ) 


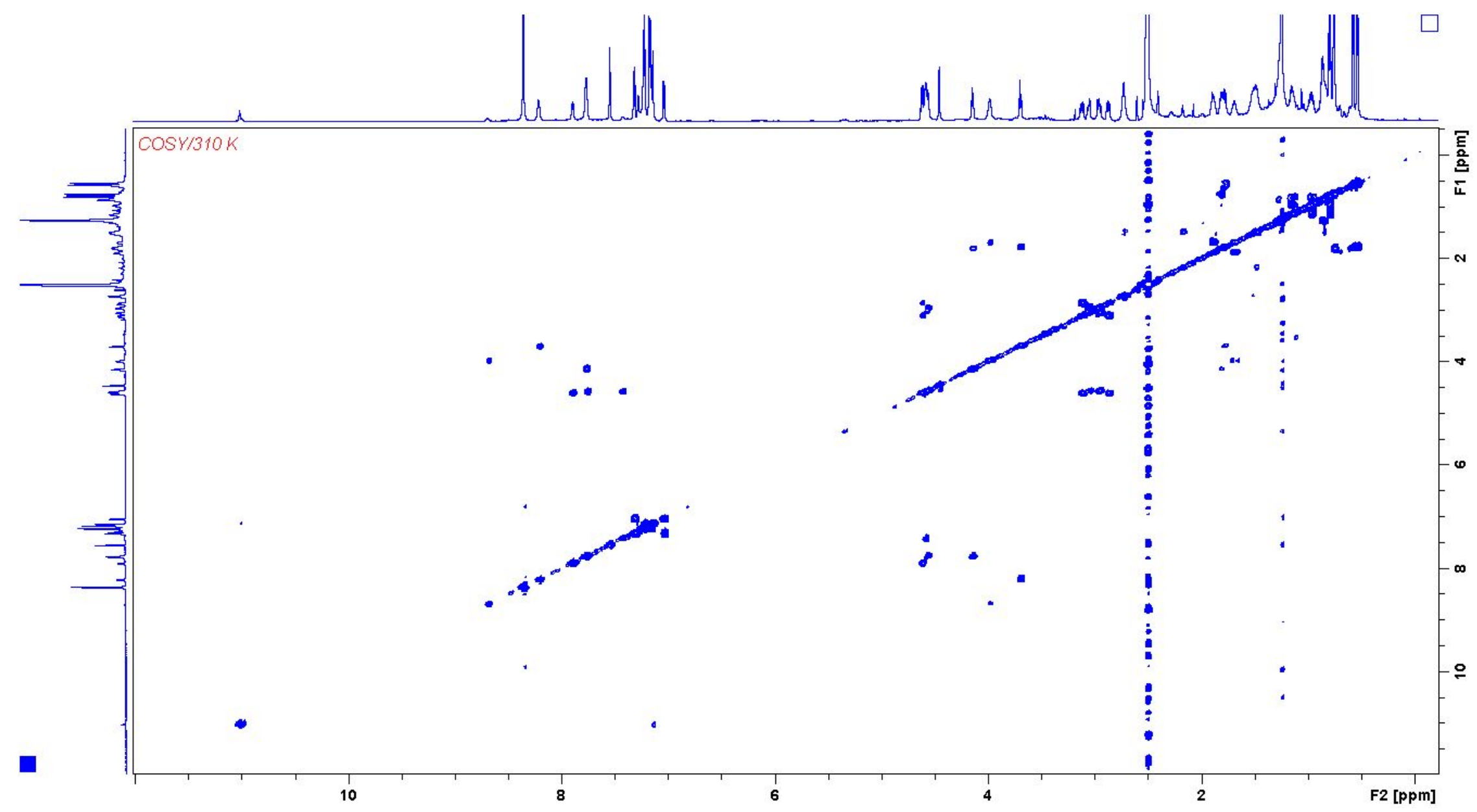

Figure S 6: COSY NMR spectrum of noursamycin A (in DMSO- $d_{6}$ ) 


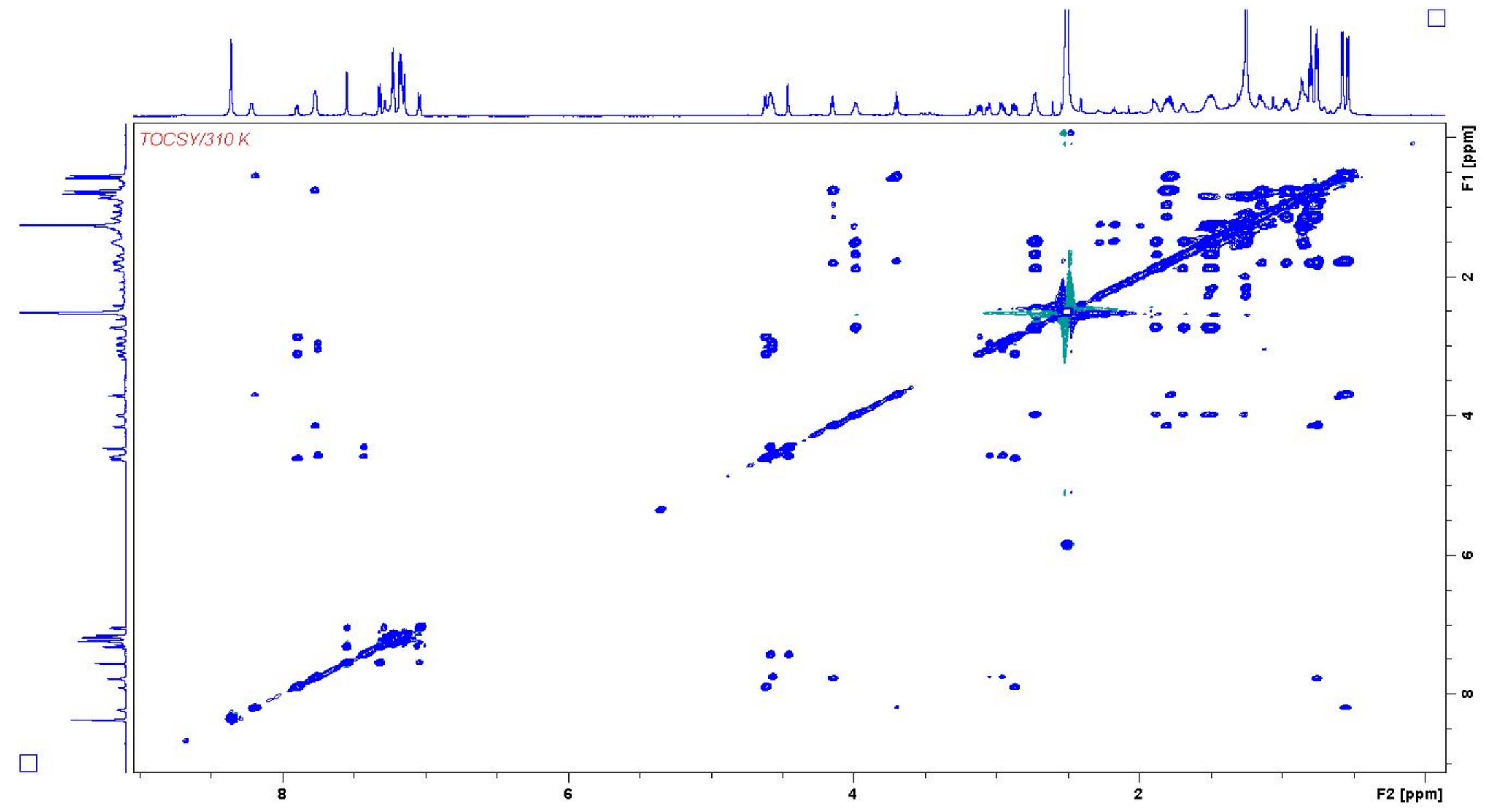

Figure S 7: TOCSY NMR spectrum of noursamycin A (in DMSO- $d_{6}$ ) 


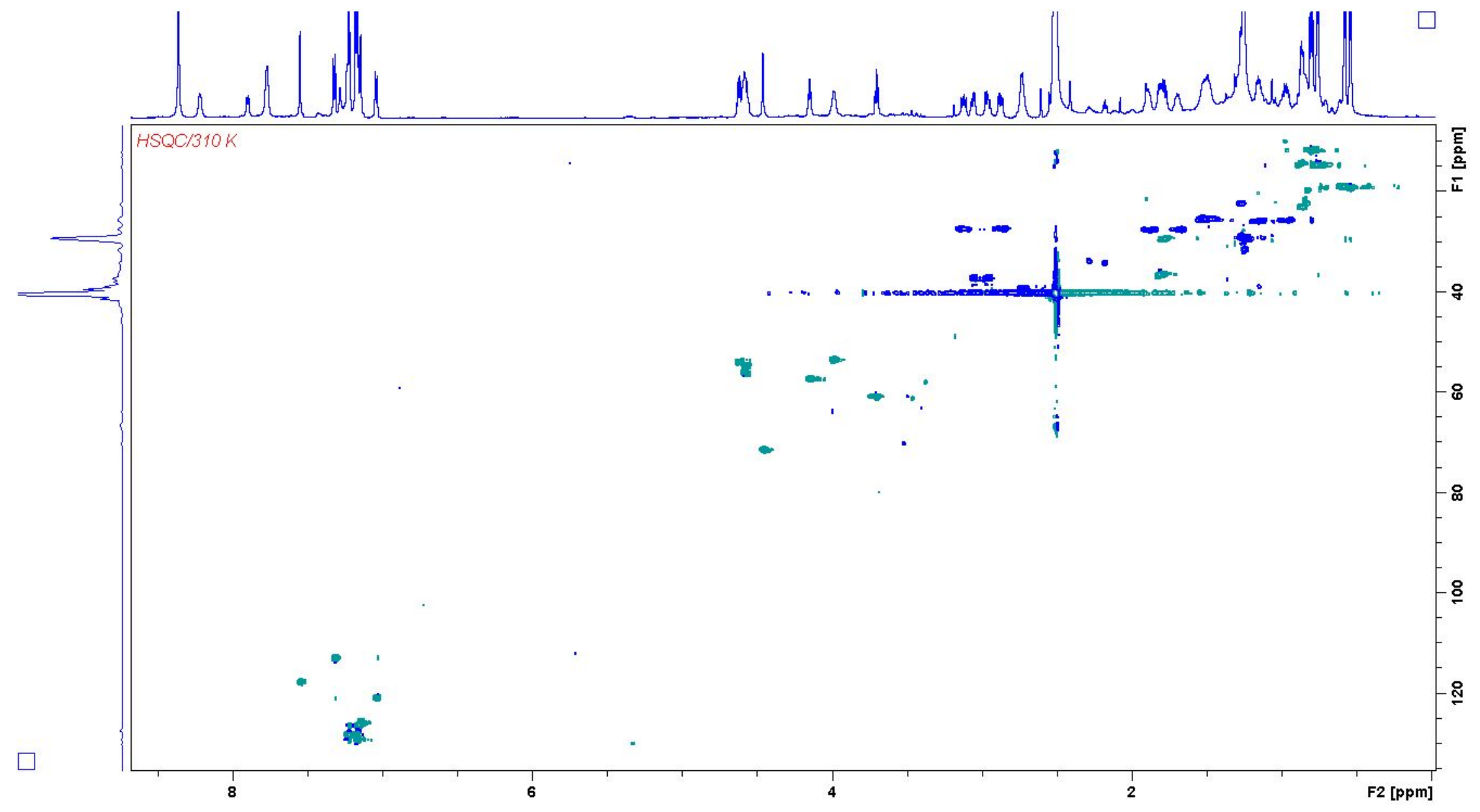

Figure S 8: HSQC NMR spectrum of noursamycin A (in DMSO-d $\mathrm{d}_{6}$ ) 


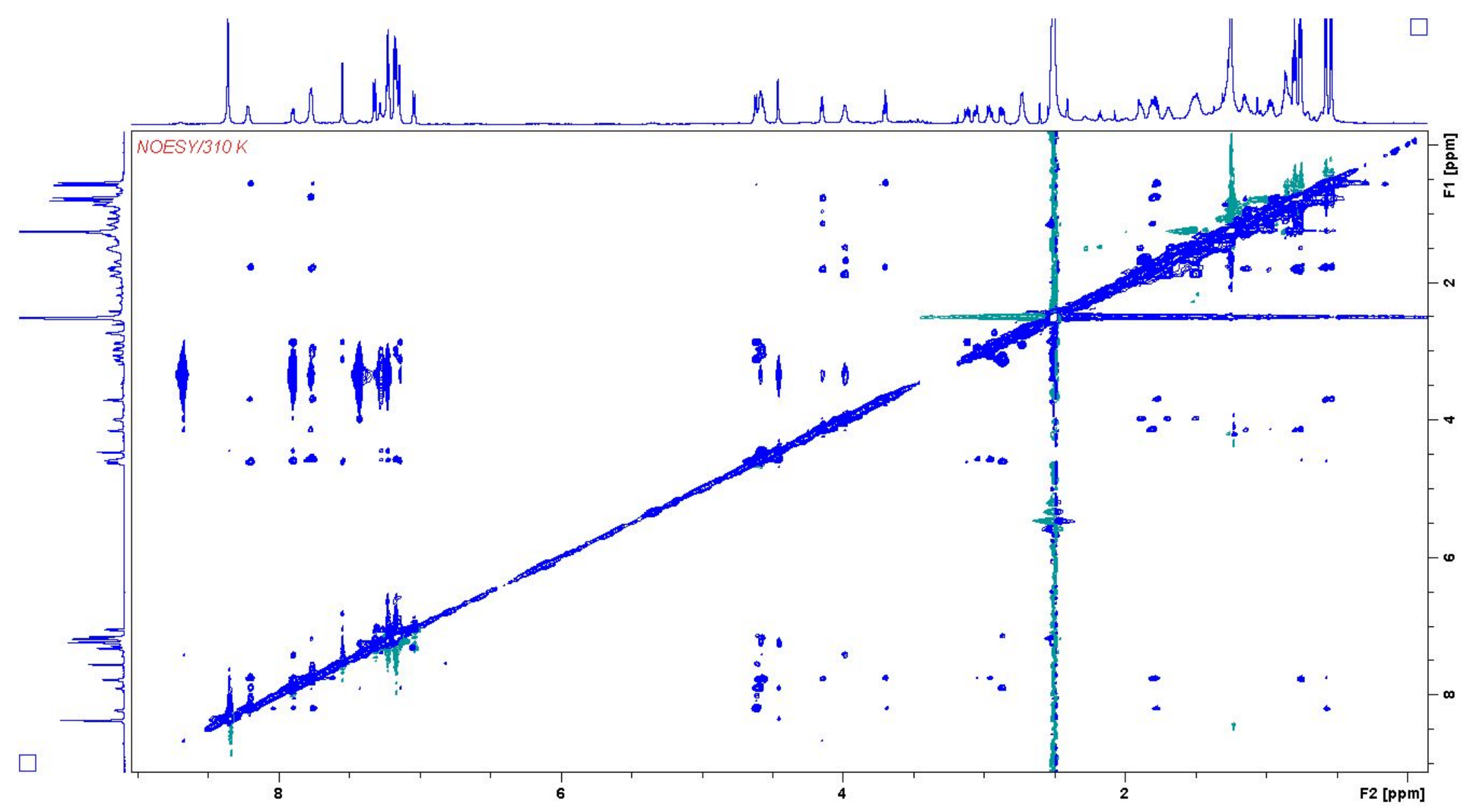

Figure S 9: NOESY NMR spectrum of noursamycin A (in DMSO-d $_{6}$ ) 


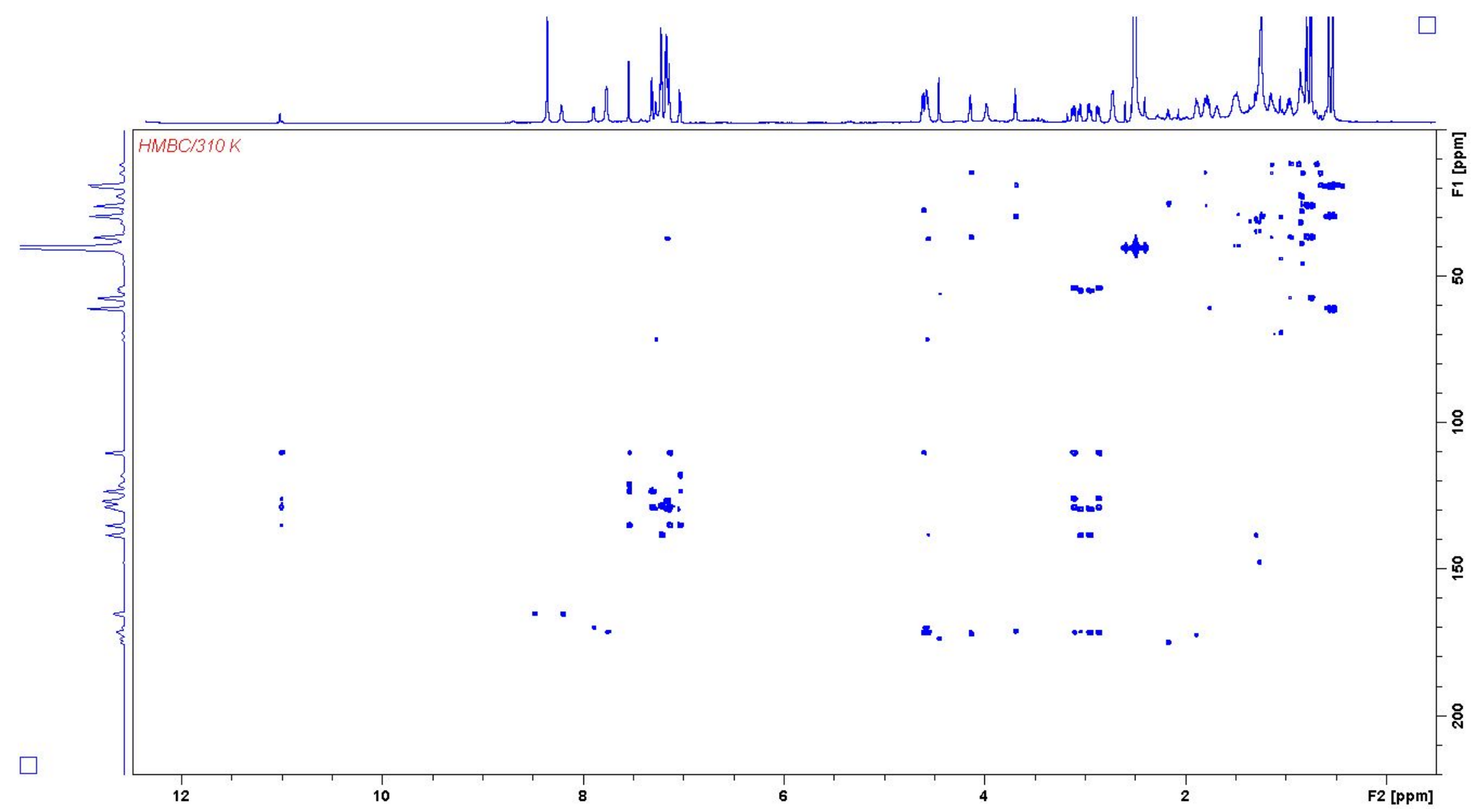

Figure S 10: HMBC NMR spectrum of noursamycin A (in DMSO- $\mathrm{d}_{6}$ ) 


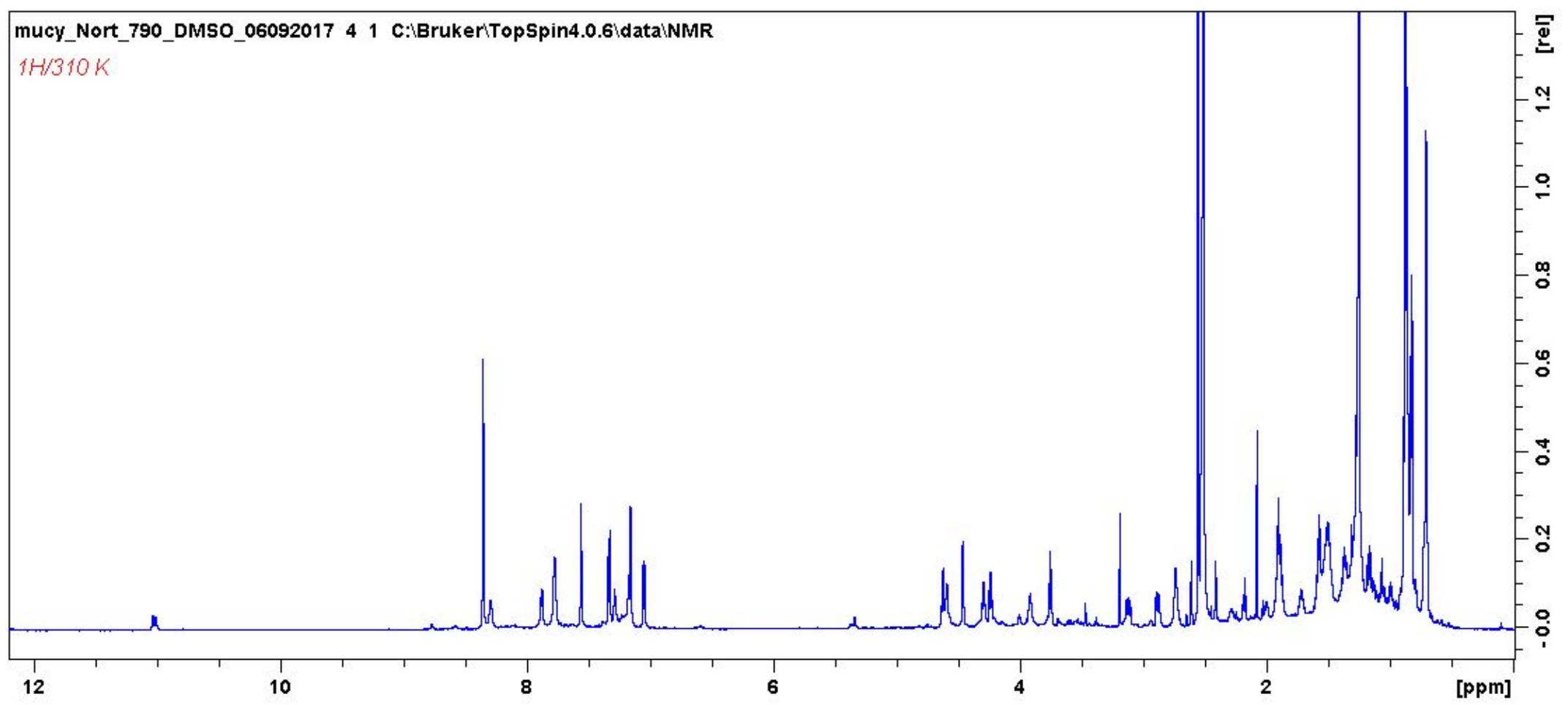

Figure S 11: Proton NMR spectrum of noursamycin B after water suppression (in DMSO- $d_{6}$ ) 


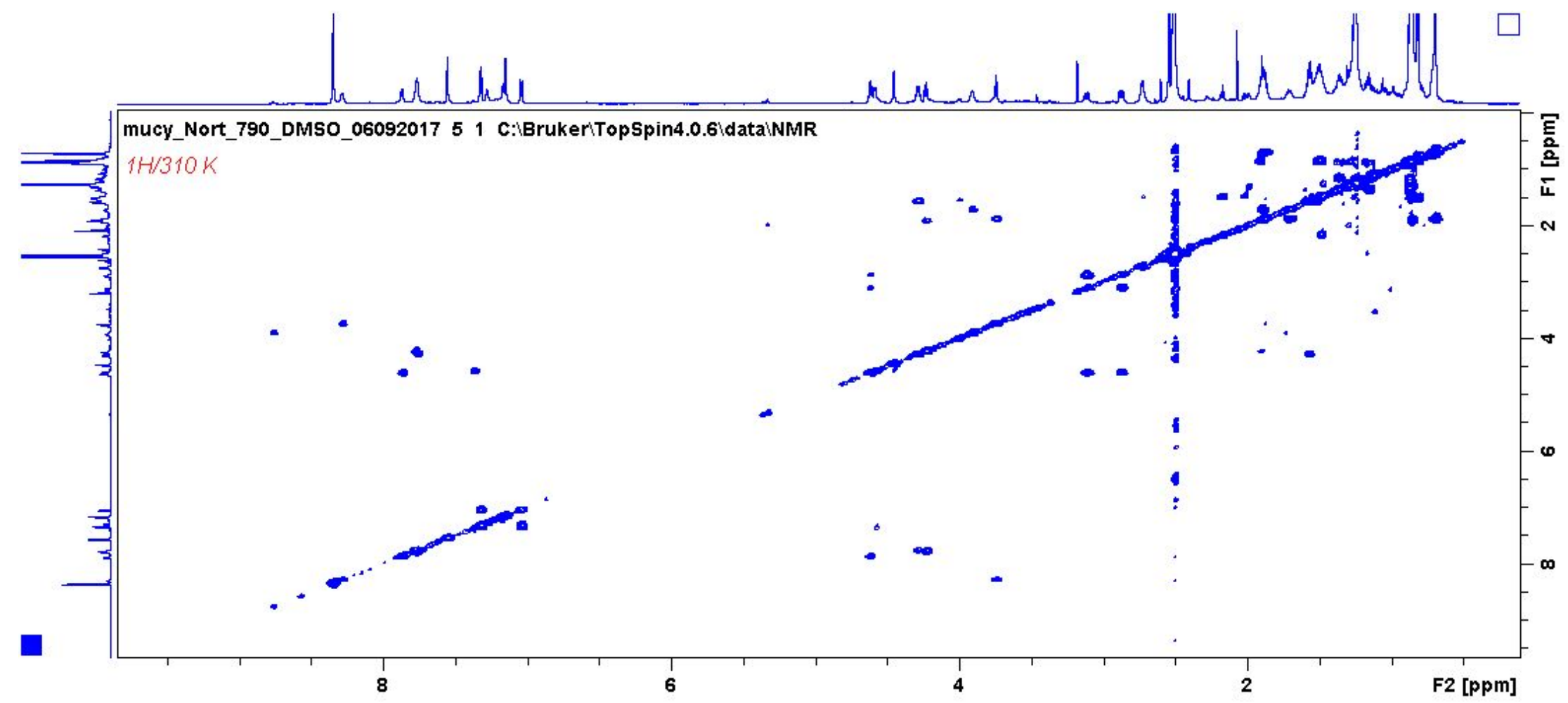

Figure S 12: COSY NMR spectrum of noursamycin B (in DMSO- $d_{6}$ ) 


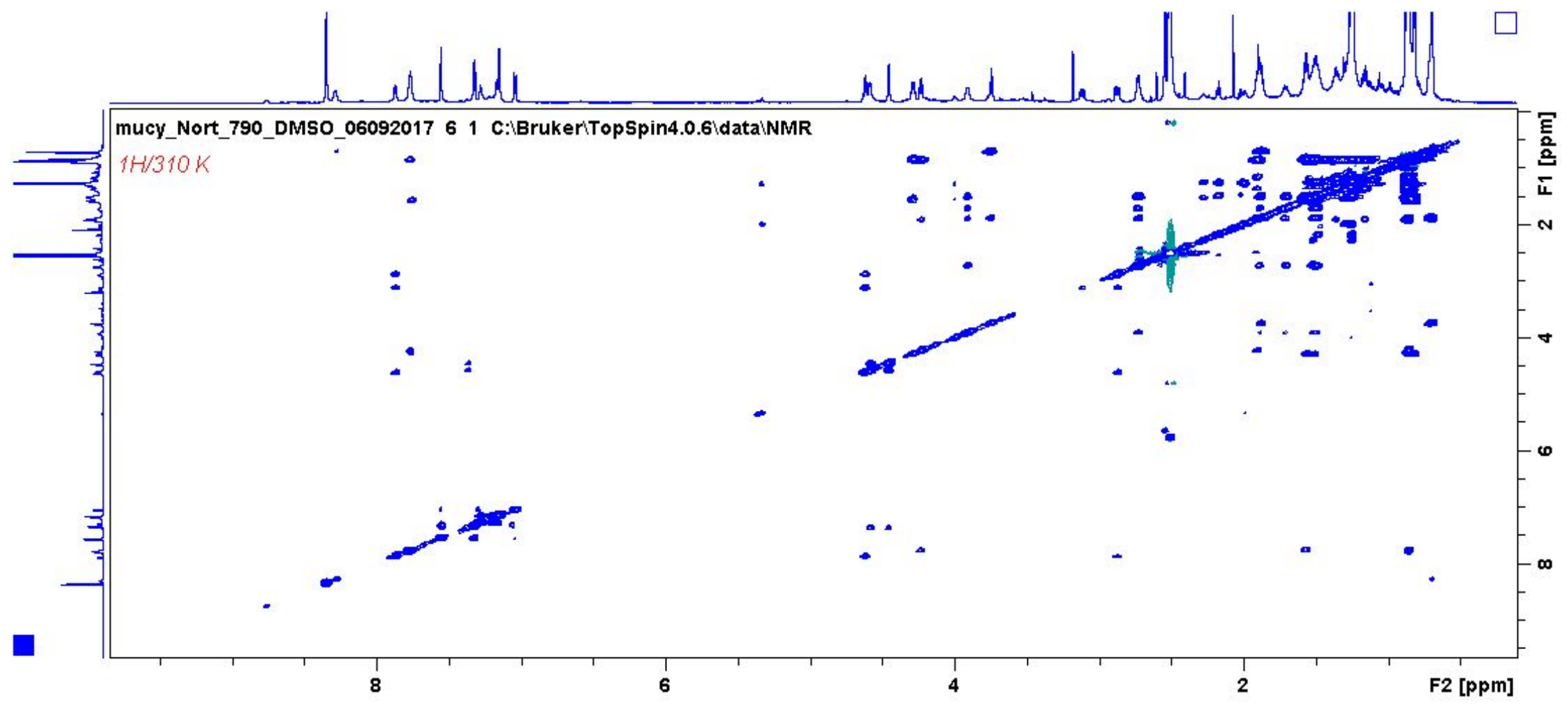

Figure S 13: TOCSY NMR spectrum of noursamycin B (in DMSO- $d_{6}$ ) 


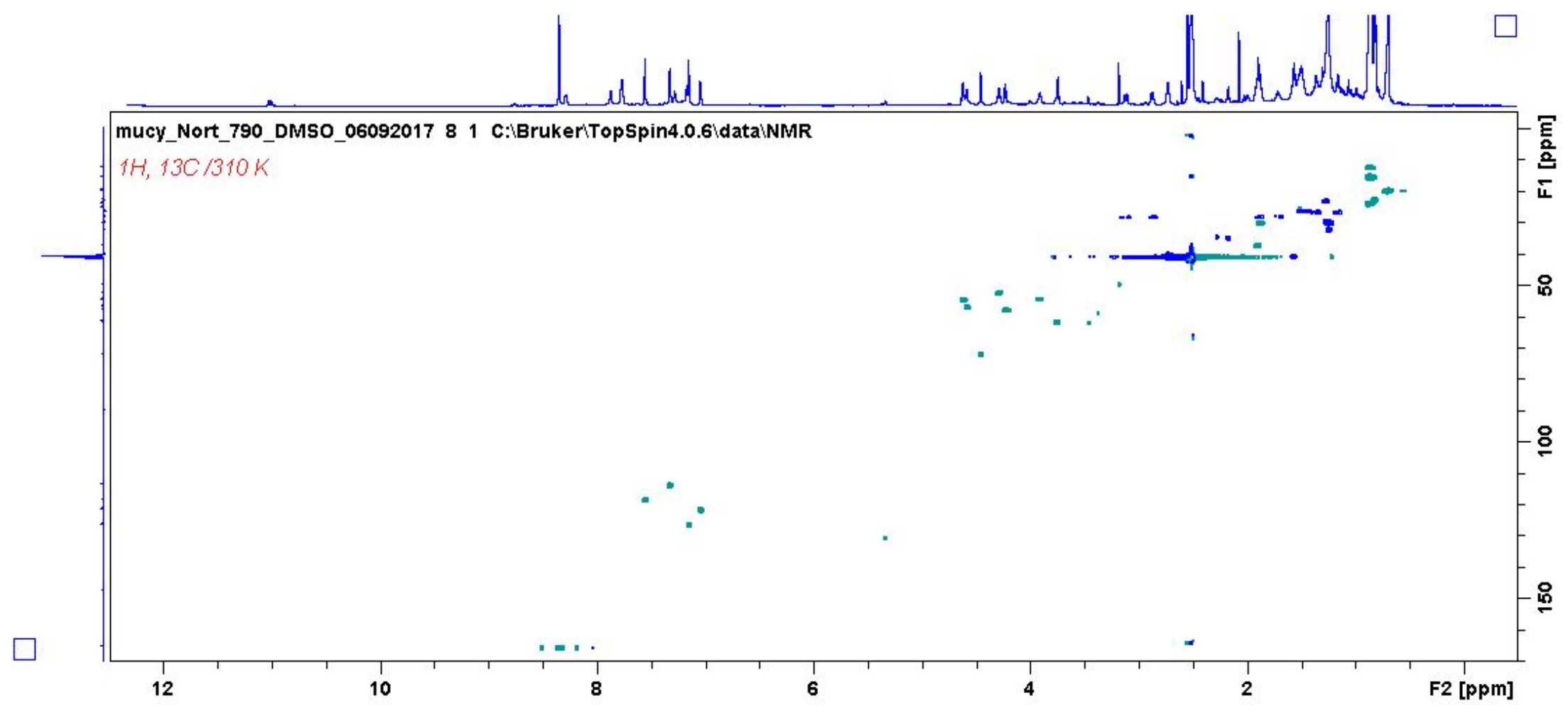

Figure S 14: HSQC NMR spectrum of noursamycin B (in DMSO- $d_{6}$ ) 


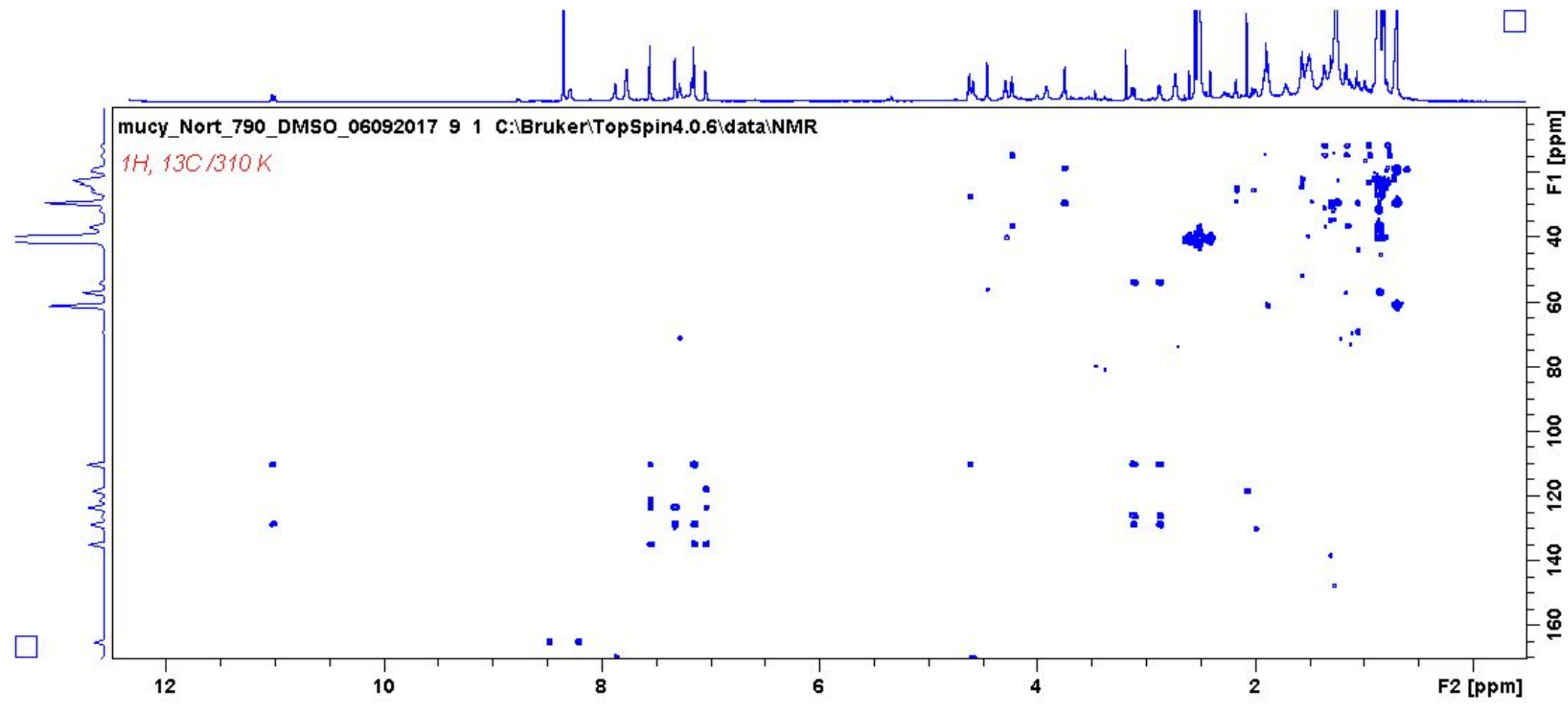

Figure S 15: HMBC NMR spectrum of noursamycin B (in DMSO- $d_{6}$ ) 


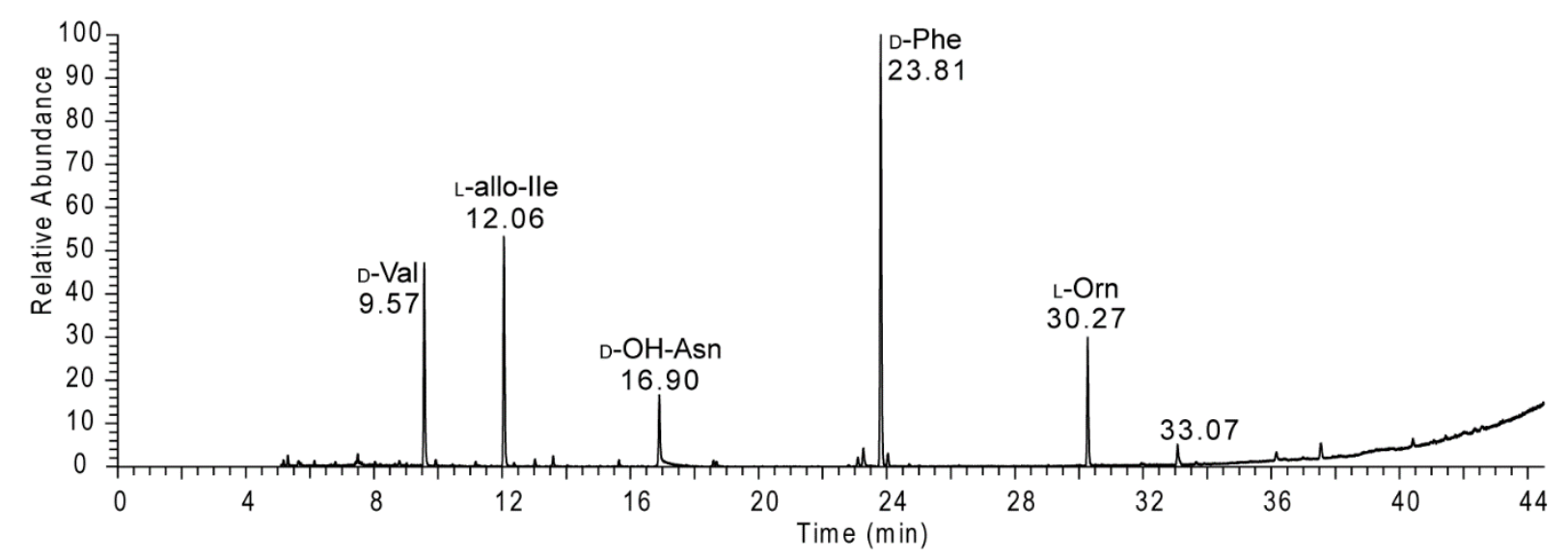

Figure S 16: GC-EI-MS chromatogram of norsamycin A

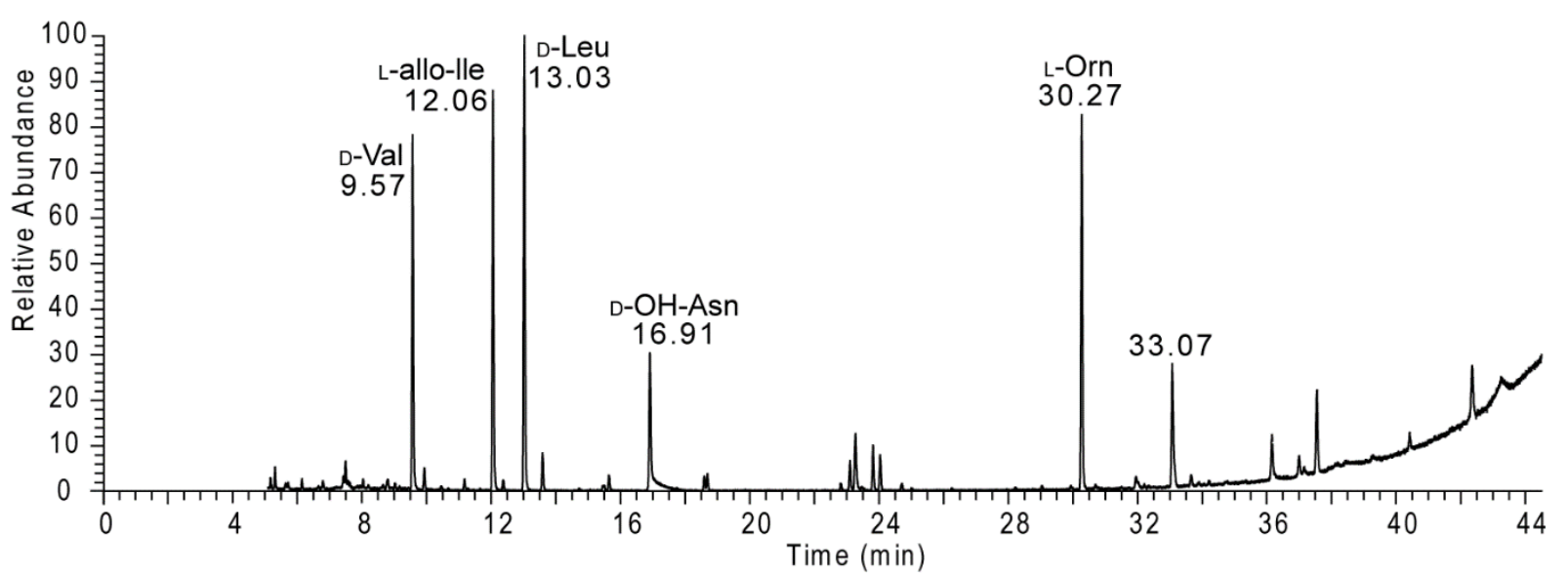

Figure S 17: GC-EI-MS chromatogram of norsamycin B 
a)

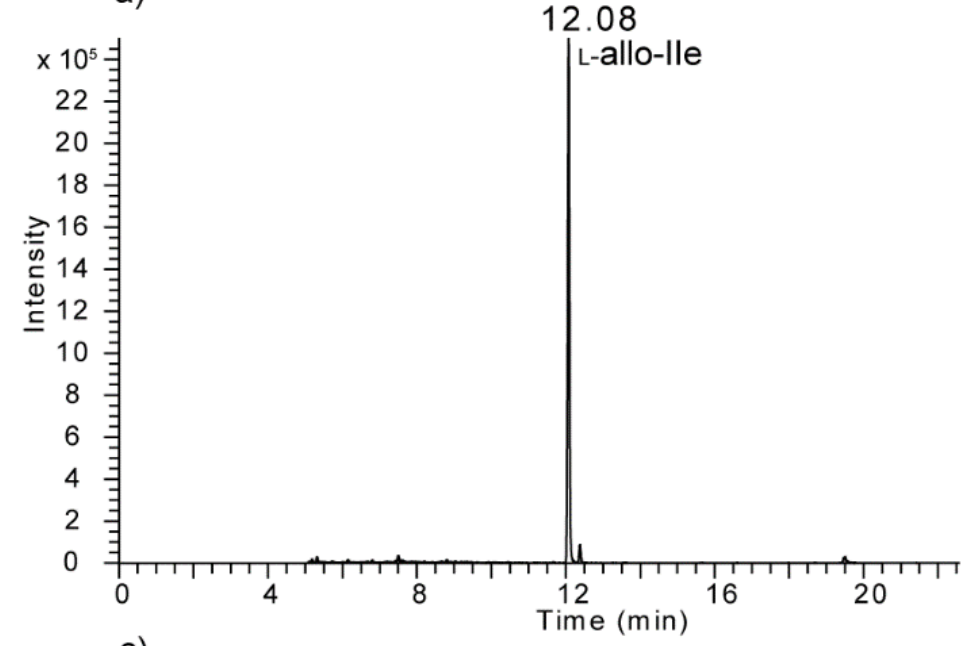

c)

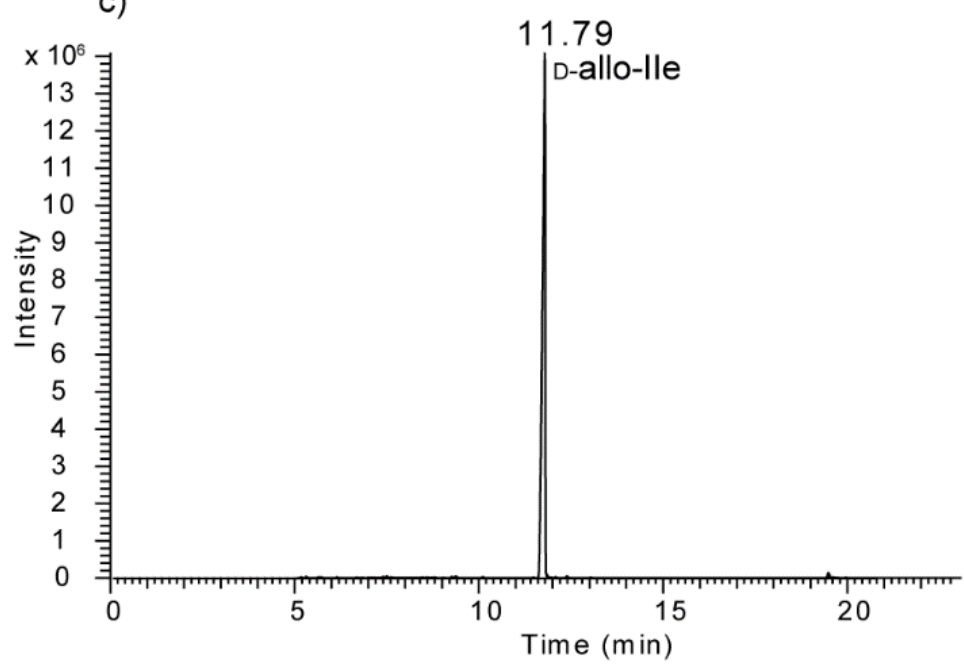

b)

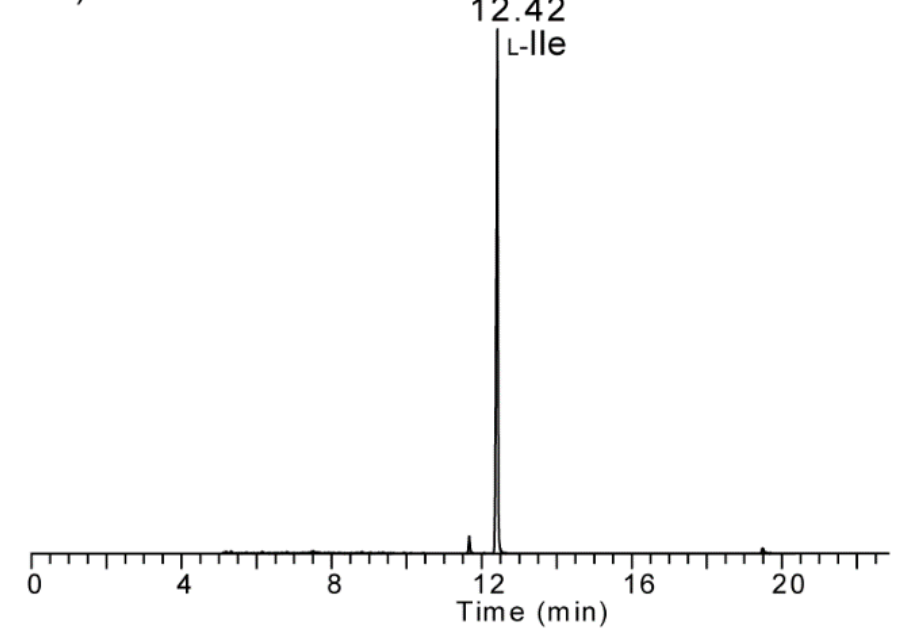

d)

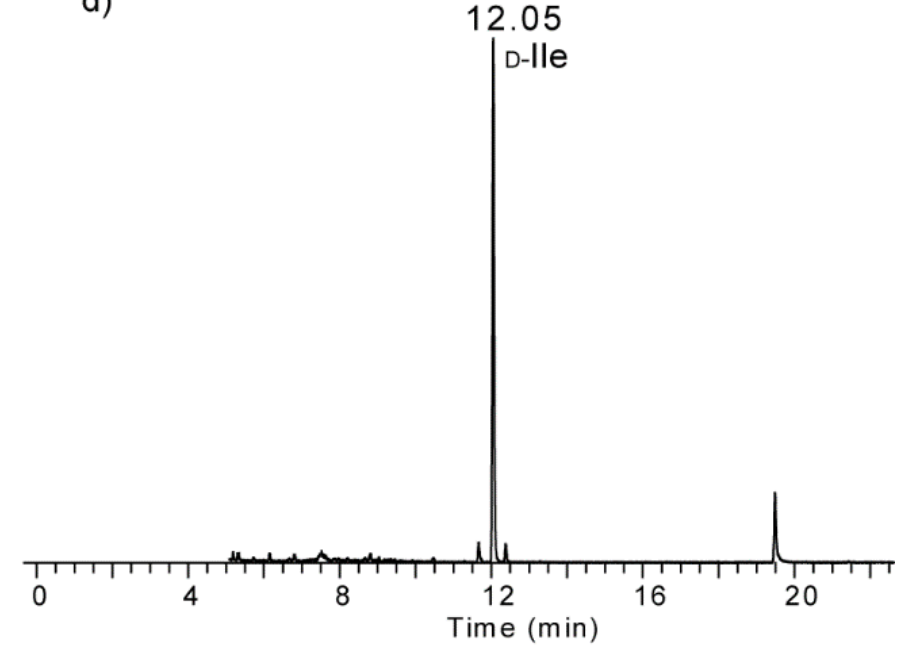

Figure S 18: Comparison of the derivatized isoleucine isomers by chiral GC-EI-MS 


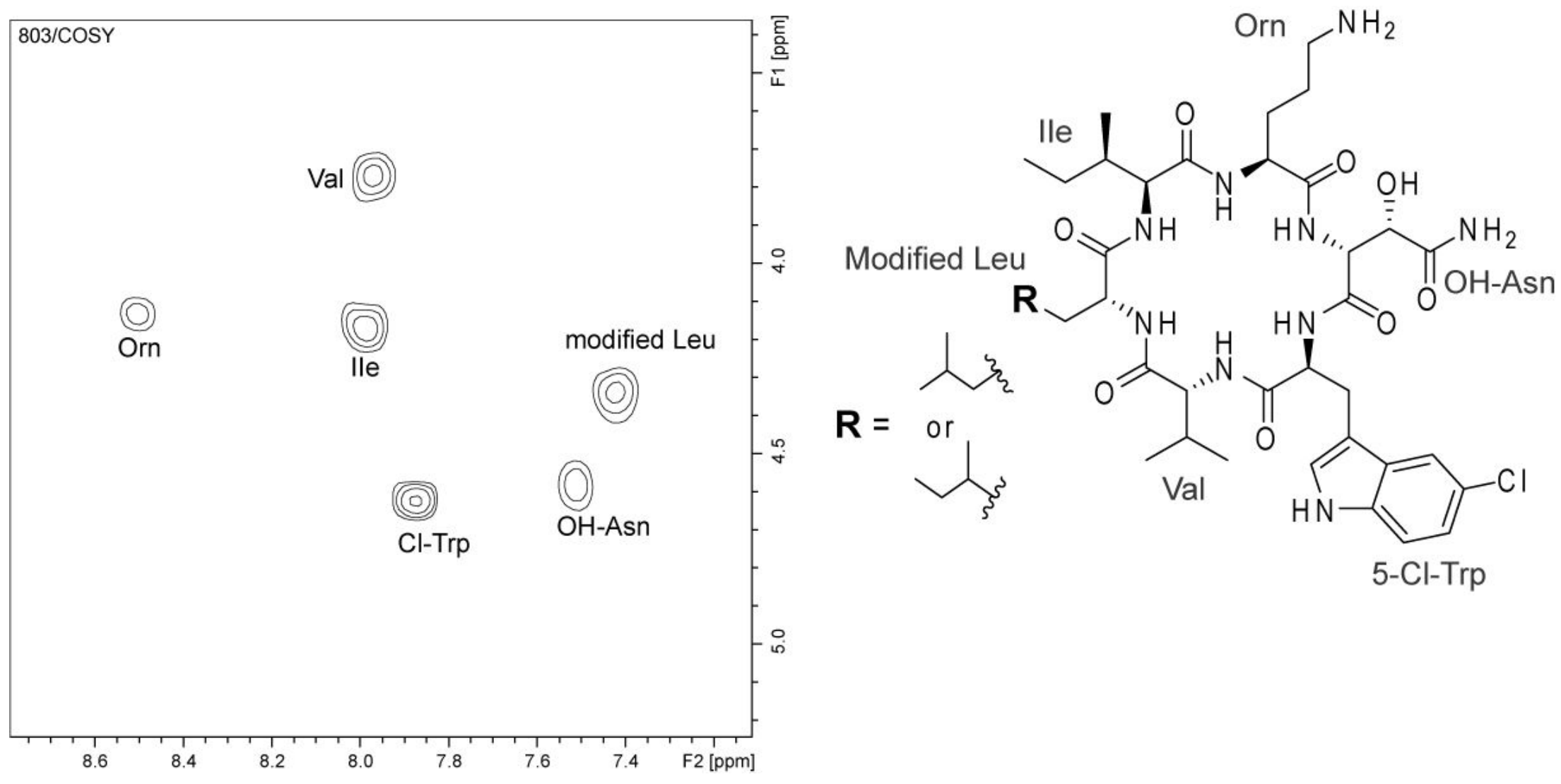

Figure S 19: Partial COSY spectrum of 803 Da peptide indicating 6-amide protons. 


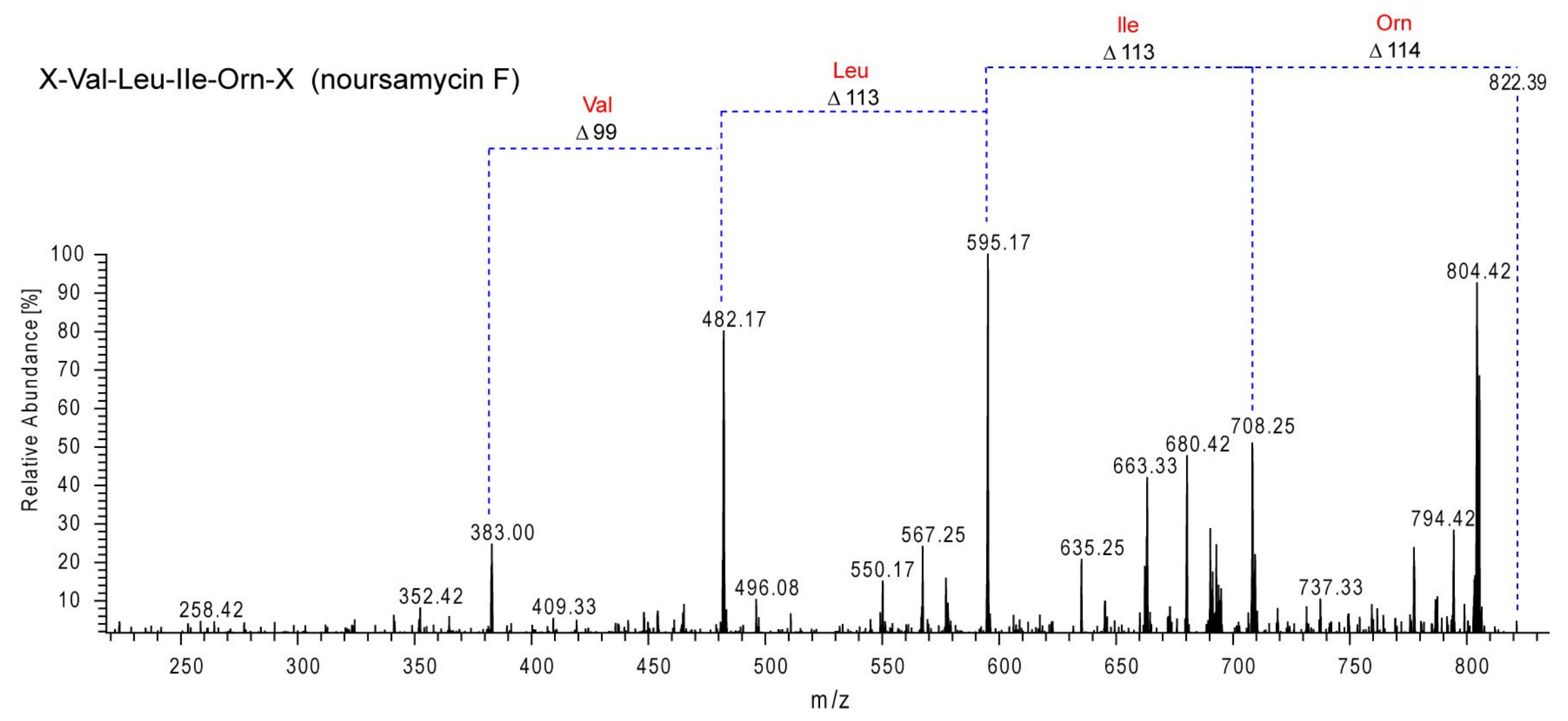

Figure S 20: The tandem MS/MS fragmentation of noursamycin F performed on an ESI-LTQ Orbitrap XL MS system 
Table S 1: Deduced NMR data from the structure elucidation of noursamycin A in DMSO- $\mathrm{d}_{6}$.

\begin{tabular}{|c|c|c|c|c|c|c|}
\hline & $\begin{array}{l}\text { Amino acid } \\
\text { Residue }\end{array}$ & Pos & $\delta \mathrm{C}$ & $\delta_{\mathrm{H}}(J$ in $\mathrm{Hz})$ & $\overline{\mathrm{COSY}}$ & $\overline{\mathrm{HMBC}}$ \\
\hline \multirow[t]{13}{*}{$\operatorname{Trp}^{1}$} & & $\mathrm{NH}$ & - & $7.89, \mathrm{~d}(7.8)$ & $\mathrm{H} \alpha$ & $\mathrm{COOH}^{6}$ \\
\hline & & $\mathrm{H} \alpha$ & $54.1, \mathrm{CH}$ & 4.61, q (7.4) & $\mathrm{H} \beta, \mathrm{NH}^{1}$ & $\begin{array}{l}3, \beta, \\
\mathrm{COOH}^{1}\end{array}$ \\
\hline & & $\mathrm{H} \beta$ & $27.5, \mathrm{CH}_{2}$ & $\begin{array}{l}3.12, \mathrm{dd}(7.1,14.2) \\
2.87, \mathrm{dd}(6.9,14.2)\end{array}$ & $\mathrm{H} \alpha$ & $\begin{array}{l}2,3,3 \mathrm{a}, \alpha \\
\mathrm{COOH}^{1}\end{array}$ \\
\hline & & 1 & - & 11.0, br s & 2 & $1,3,3 a, 7 a$ \\
\hline & & 2 & $126.0, \mathrm{CH}$ & 7.14, s & 1 & $3,3 a, 7 a$ \\
\hline & & 3 & $110.3, \mathrm{C}$ & - & - & - \\
\hline & & $3 a$ & $128.8, \mathrm{C}$ & - & - & - \\
\hline & & 4 & $118.0, \mathrm{CH}$ & $7.54, \mathrm{~s}$ & - & $3,5,6,7 \mathrm{a}$ \\
\hline & & 5 & $123.4, \mathrm{C}$ & - & - & - \\
\hline & & 6 & $121.2, \mathrm{CH}$ & $7.04, \mathrm{~d}(8.3)$ & 7 & $4,5,7 \mathrm{a}$ \\
\hline & & 7 & $113.2, \mathrm{CH}$ & $7.31, \mathrm{~d}(8.9)$ & 6 & $3 a, 5$ \\
\hline & & $7 \mathrm{a}$ & $135.1, \mathrm{C}$ & - & - & - \\
\hline & & $\mathrm{COOH}$ & $171.7, \mathrm{C}$ & - & - & - \\
\hline \multirow[t]{6}{*}{$\mathrm{Val}^{2}$} & & $\mathrm{NH}$ & - & 8.21 , br s & $\mathrm{H} \alpha$ & $\overline{\text { n.d }}$ \\
\hline & & $\mathrm{H} \alpha$ & $60.9, \mathrm{CH}$ & $3.70, \mathrm{t}(7.6)$ & $\mathrm{H} \beta, \mathrm{NH}^{2}$ & $\beta, \gamma, \mathrm{COOH}^{2}$ \\
\hline & & $\mathrm{H} \beta$ & $29.5, \mathrm{CH}$ & $1.78, \mathrm{~m}$ & $\mathrm{H} \alpha, \mathrm{H} \gamma$ & $\alpha$ \\
\hline & & $\mathrm{H} \gamma_{1}$ & $19.3, \mathrm{CH}_{3}$ & $0.54, \mathrm{~d}(6.6)$ & $\mathrm{H} \beta$ & $\alpha, \beta, \gamma_{2}$ \\
\hline & & $\mathrm{H} \gamma_{2}$ & $19.1, \mathrm{CH}_{3}$ & $0.57, \mathrm{~d}(6.6)$ & $\mathrm{H} \beta$ & $\alpha, \beta, \gamma_{1}$ \\
\hline & & $\mathrm{COOH}$ & $171.4, \mathrm{C}$ & - & - & - \\
\hline \multirow[t]{9}{*}{$\mathrm{Phe}^{3}$} & & $\mathrm{NH}$ & - & 7.76 , br s & $\mathrm{H} \alpha$ & $\mathrm{COOH}^{2}$ \\
\hline & & $\mathrm{H} \alpha$ & $54.9, \mathrm{CH}$ & $4.56, \mathrm{~m}^{\mathrm{a}}$ & $\mathrm{H} \beta, \mathrm{NH}^{3}$ & $\begin{array}{l}1, \beta, \\
\mathrm{COOH}^{3}\end{array}$ \\
\hline & & $\mathrm{H} \beta$ & $37.4, \mathrm{CH}_{2}$ & $3.06, \mathrm{dd}(6.2,13.3)$ & $\mathrm{H} \alpha$ & $\alpha, 1,2,6$ \\
\hline & & & & 2.96, dd $(8.1,13.0)$ & & \\
\hline & & 1 & $138.4, \mathrm{C}$ & - & - & - \\
\hline & & 2,6 & 129.3, CH & $7.17, \mathrm{t}^{\mathrm{a}}(6.9)$ & 3,5 & $\beta, 4,6$ or 2 \\
\hline & & 3,5 & $128.4, \mathrm{CH}$ & $7.22, \mathrm{t}(6.9)$ & 2,6 & 1,5 or 3 \\
\hline & & 4 & $126.6, \mathrm{CH}$ & $7.16, \mathrm{~d}^{\mathrm{a}}(6.9)$ & 3,5 & 2,6 \\
\hline & & $\mathrm{COOH}$ & $171.6, \mathrm{C}$ & - & - & - \\
\hline \multirow[t]{8}{*}{$\mathrm{IIe}^{4}$} & & $\mathrm{NH}$ & - & 7.77 , br s & $\mathrm{H} \alpha$ & $\mathrm{COOH}^{3}$ \\
\hline & & $\mathrm{H} \alpha$ & $57.5, \mathrm{CH}$ & $4.14, \mathrm{t}(6.5)$ & $\mathrm{H} \beta, \mathrm{NH}^{4}$ & $\begin{array}{l}\beta, \gamma, \gamma_{\mathrm{m}} \\
\mathrm{COOH}^{4}\end{array}$ \\
\hline & & $\mathrm{H} \beta$ & $36.7, \mathrm{CH}$ & $1.81, \mathrm{~m}$ & $\mathrm{H} \alpha, \mathrm{H} \gamma$ & $\alpha, \gamma, \gamma_{\mathrm{m}}$ \\
\hline & & $\mathrm{H} \gamma($ methyl) & $14.8, \mathrm{CH}_{3}$ & $0.75, \mathrm{~d}(6.8)$ & $\mathrm{H} \beta$ & $\alpha, \beta, \gamma$ \\
\hline & & $\mathrm{H} \gamma$ & 26.0, $\mathrm{CH}_{2}$ & $1.15, \mathrm{~m}$ & $\mathrm{H} \beta, \mathrm{H} \delta$ & $\alpha, \beta, \delta$ \\
\hline & $\sim n$ & & & $0.97, \mathrm{~m}$ & & \\
\hline & & $\mathrm{H} \delta$ & $11.1, \mathrm{CH}_{3}$ & $0.79, \mathrm{t}(7.2)$ & $\mathrm{H} \gamma$ & $\beta, \gamma$ \\
\hline & & $\mathrm{COOH}$ & $172.2, \mathrm{C}$ & - & - & - \\
\hline
\end{tabular}




\begin{tabular}{|c|c|c|c|c|c|c|}
\hline \multirow{7}{*}{$\operatorname{Orn}^{5}$} & \multirow{7}{*}{$\left.\mathrm{H}_{2} \mathrm{~N}\right\rangle \delta$} & \multirow{3}{*}{$\begin{array}{l}\mathrm{NH} \\
\mathrm{H} \alpha \\
\mathrm{H} \beta\end{array}$} & \multirow{3}{*}{$\begin{array}{l}171.4, \mathrm{C} \\
53.6, \mathrm{CH} \\
27.5, \mathrm{CH}_{2}\end{array}$} & 8.69 , br s & \multirow{3}{*}{$\begin{array}{l}\mathrm{H} \alpha \\
\mathrm{H} \beta, \mathrm{NH}^{5} \\
\mathrm{H} \alpha\end{array}$} & \multirow{3}{*}{$\begin{array}{l}\text { n.d } \\
\text { n.d } \\
\alpha, \delta, \mathrm{COOH}^{5}\end{array}$} \\
\hline & & & & 3.98 , br s & & \\
\hline & & & & $1.88, \mathrm{~m}$ & & \\
\hline & & $\mathrm{H} \gamma$ & $25.5, \mathrm{CH}_{2}$ & $\begin{array}{l}1.69, \mathrm{~m} \\
1.50, \mathrm{~m}\end{array}$ & $\mathrm{H} \beta, \mathrm{H} \delta$ & $\beta, \delta$ \\
\hline & & $\mathrm{H} \delta$ & $39.5, \mathrm{CH}_{2}$ & $2.72, \mathrm{~d}(5.0)$ & $\mathrm{H} \gamma$ & n.d \\
\hline & & $\mathrm{NH}_{2}$ & - & 2.17 & - & $\gamma$ \\
\hline & & $\mathrm{COOH}$ & $172.5, \mathrm{C}$ & - & - & - \\
\hline $\mathrm{OH}-$ & 2 & $\mathrm{NH}$ & - & $7.43, \mathrm{~d}(6.5)$ & $\mathrm{H} \alpha$ & n.d \\
\hline & & $\mathrm{H} \alpha$ & $56.1, \mathrm{CH}$ & $4.58, \mathrm{~m}^{\mathrm{a}}$ & $\mathrm{H} \beta, \mathrm{NH}^{6}$ & $\beta, \mathrm{COOH}^{6}$ \\
\hline & & $\mathrm{H} \beta$ & $71.6, \mathrm{CH}$ & $4.45, \mathrm{~s}$ & $\mathrm{H} \alpha$ & $\alpha, \mathrm{CO}-$ \\
\hline & & $\mathrm{CO}-$ & $173.8, \mathrm{C}$ & - & - & - \\
\hline & on & $\mathrm{NH}_{2}$ & - & 7.28 & - & - \\
\hline & & $\mathrm{COOH}$ & $170.0, \mathrm{C}$ & - & - & - \\
\hline
\end{tabular}

${ }^{\mathrm{a}}$ implies overlapping signals 
Table S 2: Predicted gene functions from the putative gene cluster.

\begin{tabular}{|c|c|c|c|c|c|}
\hline ORF & $\begin{array}{l}\text { Size } \\
{[\mathrm{bp}]}\end{array}$ & Predicted function / homology & Organism & $\begin{array}{l}\text { Accession number of } \\
\text { homologous protein }\end{array}$ & $\begin{array}{l}\text { Homology } \\
\text { similarity/ } \\
\text { identity [\%] }\end{array}$ \\
\hline 1 & 1490 & GntR family transcriptional regulator & $\begin{array}{l}\text { S. sp. } 769 \\
\text { S. gilvosporeus }\end{array}$ & $\begin{array}{l}\text { AJC55499.1 } \\
\text { WP_083104096.1 }\end{array}$ & $\begin{array}{l}100 / 97 \\
92 / 80\end{array}$ \\
\hline 2 & 1094 & $\begin{array}{l}\text { Anthranilate } \\
\text { phosphoribosyltransferase }\end{array}$ & $\begin{array}{l}\text { S. sp. } 769 \\
\text { S. yunnanensis }\end{array}$ & $\begin{array}{l}\text { WP_078876202.1 } \\
\text { WP_073450039.1 }\end{array}$ & $\begin{array}{l}100 / 99 \\
95 / 98\end{array}$ \\
\hline 3 & 785 & indole-3-glycerol phosphate synthase & $\begin{array}{l}\text { S. sp. } 769 \\
\text { S. yunnanensis }\end{array}$ & $\begin{array}{l}\text { AJC55501.1 } \\
\text { WP_073450040.1 }\end{array}$ & $\begin{array}{l}100 / 98 \\
100 / 97\end{array}$ \\
\hline 4 & 1697 & 2-isopropylmalate synthase & $\begin{array}{l}\text { S. yunnanensis } \\
\text { S. sp. } 769\end{array}$ & $\begin{array}{l}\text { WP_079182451.1 } \\
\text { AJC55502.1 }\end{array}$ & $\begin{array}{l}100 / 97 \\
100 / 97\end{array}$ \\
\hline 5 & 881 & amidinotransferase & $\begin{array}{l}\text { S. sp. } 769 \\
\text { S. yunnanensis }\end{array}$ & $\begin{array}{l}\text { WP_052286707.1 } \\
\text { WP_073450042.1 }\end{array}$ & $\begin{array}{l}100 / 98 \\
100 / 97\end{array}$ \\
\hline 6 & 545 & NADH-FMN oxidoreductase & $\begin{array}{l}\text { S. yunnanensis } \\
\text { S. sp. } 769\end{array}$ & $\begin{array}{l}\text { SHN } 33124.1 \\
\text { AJC55504.1 }\end{array}$ & $\begin{array}{l}100 / 98 \\
98 / 97\end{array}$ \\
\hline 7 & 1256 & Sodium/hydrogen exchanger & $\begin{array}{l}\text { S. yunnanensis } \\
\text { S. sp. } 769\end{array}$ & $\begin{array}{l}\text { WP_073450044.1 } \\
\text { WP_052286708.1 }\end{array}$ & $\begin{array}{l}100 / 98 \\
100 / 98\end{array}$ \\
\hline 8 & 1550 & $\begin{array}{l}\text { Tryptophan halogenase } \\
*[\text { tryptophan } 7 \text {-halogenase }]\end{array}$ & $\begin{array}{l}\text { S. noursei } \\
* \text { S. yunnanensis } \\
\text { S. sp. } 769\end{array}$ & $\begin{array}{l}\text { WP_079142554.1 } \\
\text { WP_073450046.1 } \\
\text { WP } 078875718.1\end{array}$ & $\begin{array}{l}100 / 100 \\
100 / 96 \\
100 / 96\end{array}$ \\
\hline 9 & 515 & $\begin{array}{l}\text { Aminoacyl-tRNA editing domain } \\
\text { protein }\end{array}$ & $\begin{array}{l}\text { S. yunnanensis } \\
\text { S. sp. } 769\end{array}$ & $\begin{array}{l}\text { WP_052286709.1 } \\
\text { WP_073450048.1 }\end{array}$ & $\begin{array}{l}100 / 98 \\
100 / 98\end{array}$ \\
\hline 10 & 1112 & $\begin{array}{l}\text { branched-chain amino acid } \\
\text { aminotransferase }\end{array}$ & $\begin{array}{l}\text { S. sp. } 769 \\
\text { S. yunnanensis }\end{array}$ & $\begin{array}{l}\text { WP_039632066.1 } \\
\text { WP_073450050.1 }\end{array}$ & $\begin{array}{l}100 / 99 \\
100 / 98\end{array}$ \\
\hline 11 & 386 & SnoaL domain protein & $\begin{array}{l}\text { S. yunnanensis } \\
\text { S. sp. } 769\end{array}$ & $\begin{array}{l}\text { WP_073450052.1 } \\
\text { WP_039640713.1 }\end{array}$ & $\begin{array}{l}100 / 98 \\
87 / 98\end{array}$ \\
\hline 12 & 1016 & Dioxygenase & $\begin{array}{l}\text { S. yunnanensis } \\
\text { S. sp. } 769\end{array}$ & $\begin{array}{l}\text { WP_073450054.1 } \\
\text { WP_039632068.1 }\end{array}$ & $\begin{array}{l}100 / 99 \\
100 / 98\end{array}$ \\
\hline 13 & 212 & MbtH family protein [Streptomyces] & $\begin{array}{l}\text { [Streptomyces] } \\
\text { S. acidiscabies } \\
\text { S. scopuliridis }\end{array}$ & $\begin{array}{l}\text { WP_039632070.1 } \\
\text { WP_010357635.1 } \\
\text { WP } 030349232.1\end{array}$ & $\begin{array}{l}100 / 100 \\
100 / 73 \\
97 / 69\end{array}$ \\
\hline 14 & 7901 & $\begin{array}{l}\text { NRPS } \\
\text { peptide synthetase ScpsB }\end{array}$ & $\begin{array}{l}\text { S. sp. } 769 \\
\text { S. yunnanensis }\end{array}$ & $\begin{array}{l}\text { WP_052286711.1 } \\
\text { WP_073450056.1 }\end{array}$ & $\begin{array}{l}100 / 98 \\
100 / 97\end{array}$ \\
\hline 15 & 14198 & $\begin{array}{l}\text { Non-ribosomal peptide synthase } \\
\text { (NRPS) }\end{array}$ & $\begin{array}{l}\text { S. sp. } 769 \\
\text { S. yunnanensis }\end{array}$ & $\begin{array}{l}\text { WP_052286712.1 } \\
\text { WP_073449206.1 }\end{array}$ & $\begin{array}{l}100 / 96 \\
99 / 96\end{array}$ \\
\hline 16 & 1319 & $\begin{array}{l}\text { Beta-lactamase class } \mathrm{C} \text { and other } \\
\text { penicillin binding proteins }\end{array}$ & $\begin{array}{l}\text { S. sp. } 769 \\
\text { S. viridochromogenes } \\
\text { Tue } 57\end{array}$ & $\begin{array}{l}\text { AJC55515.1 } \\
\text { ELS53338.1 }\end{array}$ & $\begin{array}{l}97 / 97 \\
90 / 53\end{array}$ \\
\hline 17 & 416 & Chaperone-like protein & $\begin{array}{l}\text { S. yunnanensis } \\
\text { S. sp. } 769\end{array}$ & $\begin{array}{l}\text { WP_073449207.1 } \\
\text { WP_039640719.1 }\end{array}$ & $\begin{array}{l}100 / 99 \\
100 / 98\end{array}$ \\
\hline 18 & 2747 & $\mathrm{ABC}$ transporter permease & $\begin{array}{l}\text { S. sp. } 769 \\
\text { S. yunnanensis }\end{array}$ & $\begin{array}{l}\text { WP_063777445.1 } \\
\text { WP_073449208.1 }\end{array}$ & $\begin{array}{l}100 / 98 \\
99 / 98\end{array}$ \\
\hline 19 & 800 & ABC transporter ATP-binding protein & $\begin{array}{l}\text { S. sp. } 769 \\
\text { S. yunnanensis }\end{array}$ & $\begin{array}{l}\text { WP_039632072.1 } \\
\text { WP_079182366.1 }\end{array}$ & $\begin{array}{l}100 / 99 \\
100 / 99\end{array}$ \\
\hline 20 & 1211 & $\begin{array}{l}\text { Integral membrane sensor signal } \\
\text { transduction histidine kinase }\end{array}$ & $\begin{array}{l}\text { S. sp. } 769 \\
\text { S. yunnanensis }\end{array}$ & $\begin{array}{l}\text { WP_039632074.1 } \\
\text { WP_073449210.1 }\end{array}$ & $\begin{array}{l}100 / 99 \\
100 / 99\end{array}$ \\
\hline 21 & 671 & $\begin{array}{l}\text { LuxR family two component } \\
\text { transcriptional regulator }\end{array}$ & $\begin{array}{l}\text { [Streptomyces] } \\
\text { S. celluloflavus }\end{array}$ & $\begin{array}{l}\text { WP_039632076.1 } \\
\text { P_052860909.1 }\end{array}$ & $\begin{array}{l}100 / 99 \\
99 / 91\end{array}$ \\
\hline
\end{tabular}

